\title{
AGOUROS DE UM ESPELHO PARTIDO: LUTA E RESISTÊNCIA NO PROCESSO DE AFIRMAÇÃO ÉTNICA DOS ÍNDIOS DO NORDESTE - O CASO DOS TAPUIAS-KARIRIS DE SÃO BENEDITO
}

DANIELLE ARAÚJO ${ }^{1}$

UNILA

\begin{abstract}
RESUMO: Este artigo tem como propósito apresentar parte da pesquisa de campo sobre o processo de afirmação étnica dos Tapuia-Kariri de São Benedito - comunidade coletiva indígena do estado do Ceará. A análise resulta de uma etnografia entre os Tapuias e das observações realizadas junto a outras comunidade indígenas do Ceará, na condição de docente do magistério indígena da Secretária de Educação do Estado do Ceará (SEDUC). Os TapuiasKariris constituem o grupo mais recente a autoafirmar-se como indígena. No processo de autoafirmação e reconhecimento, a primeira dificuldade que o grupo enfrenta é a negação social em reconhecê-los enquanto indígenas. Diante dessa rejeição, o grupo está constantemente negociando e afirmando sua identidade. Esse processo é realizado por meio da reelaboração das imagens, da cultura material e das práticas culturais, elementos coletivos que passam a ser concebidos pelo prisma de pertença étnica. A cultura material e o conjunto de práticas e de saberes a ela incorporada ocupam um lugar central no cotidiano desses grupos indigenas. Advindos de conhecimentos ancestrais, os objetos, assim como as danças, as músicas e os rituais, narram de modo particular a vida e a concepção cosmológica. Analisar o processo de afirmação, suas dificuldades intrínsecas, bem como o papel das manifestações culturais e das imagens, é o objetivo deste trabalho.
\end{abstract}

PALAVRA-CHAVE: cultura material; imagem; indígena.

ABSTRACT: The purpose of this article is to present part of field research on the ethnic affirmation process of the Tapuias-Kariris from São Benedito - an indigenous collective community in Ceará/Brazil. The analysis results from an ethnography among Tapuias and observations conducted with others indigenous communities from Ceará. The Tapuias-Kariris are the latest group to self declare themselves as indigenous. In the process of self-affirmation and recognition, the first challenge faced by the group is the social refusal to recognize them as indigenous. Faced with this rejection, the group is constantly negotiating and affirming their identity. This process is performed through the reworking of the images, the material culture and cultural practices, collective elements that are now designed by the prism of ethnic belonging. Material culture and the set of practices and knowledge incorporated have a central role in the daily life of these indigenous groups. Arising from ancestral knowledge, the objects, as well as dances, songs and rituals, narrate the life and cosmological conception in a particular way. Analyzing the process of affirmation, its inherent difficultie,s as well as the role of cultural events and images, is the objective of this work.

\footnotetext{
${ }^{1}$ Doutora em Antropologia pela Universidade Federal do Rio Grande do Sul (UFRGS). Docente da Universidade Federal da Integração Latino-americana (UNILA). E-mail: danielle.araujo@ unila.edu.br .
} 
KEYWORD: material culture; image; indigenous.

\section{Introdução}

A categoria "índio" nasce com o descobrimento do chamado Novo Mundo em fins da Idade Média. Antes as terras do continente americano eram habitadas por grupos disseminados e heterogêneos. Na América de colonização espanhola e portuguesa, o descobrimento significou o massacre e a usurpação de milhares de indígenas - cicatriz indelével que une em um só tempo a história dos países latino-americanos.

No Brasil, a história geral dos grupos indígenas é difusa. As primeiras informações são provenientes de viajantes e de missionários da coroa portuguesa, que descreveram, em imagens e cartas, informações sobre a organização social, parentesco e manifestações culturais. Nesse contexto, as imagens e a cultura material, assim como os saberes a elas incorporados, formam uma opção prática e, ao mesmo tempo, simbólica de transmissão e manutenção dos saberes ancestrais. A capacidade de os grupos humanos criarem e ressignificarem materialmente a vida social permite não só a sobrevivência, mas também a vivência de elementos fundamentais da história. Assim, este trabalho de pesquisa tem o propósito de apresentar como o grupo indígena Tapuia-Kariri, de São Benedito (CE), tem lutado para afirmar sua identidade indígena apesar das dificuldades e da rejeição social. Os Tapuias-Kariris - grupo localizado no município de São Benedito, a 350 quilômetros de Fortaleza - são considerados o último grupo indígena a assumir uma identidade indígena na região nordestina.

Os Tapuias iniciaram o processo de autoafirmação em 2008. O / Encontro dos Índios Kariris marcou a tomada da luta pela afirmação. Nesse encontro estiveram presentes integrantes da municipalidade e da Universidade Regional do Cariri.

Desde então prossegue a luta pela demarcação das terras e pelo reconhecimento. Nesse processo, o grupo utiliza uma série de 
elementos da cultura material e imagens, elementos que ora correspondem, ora rompem com um imaginário cristalizado sobre o ser indígena.

\section{O papel do Estado no processo de autoafirmação}

Nas últimas décadas, alguns países latino-americanos têm elaborado políticas que visam atender à diversidade cultural do continente. Seja no campo da saúde e ou no da educação, tem se buscado atender às demandas das ditas minorias, secularmente esquecidas e ou silenciadas.

No caso dos grupos indígenas, a demanda pela demarcação das terras sempre esteve presente. Junto a essa demanda está a busca pelo acesso à saúde e a uma educação diferenciada que permita a inclusão social. Essas demandas atentam para a necessidade de uma existência cidadã sem deixar de lado a dimensão cultural, que orienta as demandas e o sentido de existência dos grupos.

Recentemente, na década de 1990, o Brasil iniciou a descentralização administrativa das políticas direcionadas aos povos indígenas. Em 1995 foram construídos marcos jurídicos e estabelecidos a interculturalidade e o bilinguismo, a partir de então aceitos como fundamento político. A partir de 1995, as secretárias estaduais de educação passaram a solicitar recursos para o financiamento dos projetos na área.

No estado do Ceará, a reforma da educação indígena está diretamente influenciada pelos organismos internacionais. A relação entre as agências multilaterais de financiamento e o Estado fez com que se avançasse um pouco mais cedo nas políticas de educação em relação a outros estados do Nordeste (ZIBAS apud AIRES, 2009). Em meados de 1990, já é esboçado um discurso em sintonia com as diretrizes políticas nacionais. Em 1996, temos a implementação de políticas específicas de educação infantil, educação especial e educação indígena. Em 1998, a Secretaria de Estadual de Educação coloca em prática, no Ceará, o Programa de Expansão da Escola Indígena.

Esse programa estava dividido em cinco metas: 
- elaboração de um censo escolar indígena;

- $\quad$ formação de professores indígenas;

- $\quad$ ampliação e construção de prédios escolares;

- elaboração de material didático;

- realização de eventos.

A efetividade das políticas modificou, paulatinamente, o censo sobre a presença indígena no Ceará. Grupos que há anos vinham travando lutas pela afirmação e pelo reconhecimento de sua indianidade foram fortalecidos e esse fortalecimento passou a servir de apoio para o surgimento e para a retomada de novas coletividades indígenas. Inicialmente tivemos os Tapebas, logo em seguida os Tremembés, os Pitaguari, os Jenipapo Kanidés, os Kanidés, os Kalabaças, os Potiguarás, os Tabajaras, os Tupinambás, os Anacés, os Paupinas, os Gaviões, os Tupibas e, por último, os Tapuias-Kariris.

Os grupos em diálogo e ou em reivindicação com a esfera estatal mantêm encontros sistemáticos e organizados para assegurar seus direitos. Há uma ampla bibliografia que procura analisar e apresentar as assembleias e os encontros das coletividades indígenas no Ceará. Tratase de assunto extenso e complexo demais para ser tratado nos limites do presente trabalho.

O fato é que, no Ceará, a criação das escolas diferenciadas foi um marco importante para cada grupo. Ou seja, se, no decorrer do longo passado, foi a educação na sua perspectiva homogeneizante que provocou a perda da cultura, a educação também pode ser um instrumento de retomada. Invariavelmente, os discursos sobre a "perda" cultural são uma realidade de todos os grupos indígenas em território nacional, no Ceará não é diferente. Essas afirmações ecoam nos mais diferentes grupos e em todas as instâncias daqueles que trabalham e atuam no movimento.

O antropólogo Augusto dos Santos Laranjeiras Sampaio (1986) enfatiza que mais importante do que reproduzir o discurso da perda, o que remete a uma noção saudosista da cultura, ou à crença na existência de uma cultura indígena originária, o coerente é questionar o porquê da perda. O que mais importa questionar, então, é qual foi a causa da suposta perda cultural e como acabou ocorrendo o processo de assimilação. Juntamente com Sampaio, considero, então, que tão 
coerente quanto indagar sobre perda é pesquisar sobre as formas de permanência e as mudanças que se fazem necessárias.

No Brasil, as dificuldades de acesso à educação formal e à saúde pública, além da permanente luta pela conquista de direitos variados, não destoam do que acontece em outros países latino-americanos, onde imperam a luta e as demandas pelo reconhecimento. $O$ fato é que a miscigenação forjada no período pós-colonial, propagada por intelectuais e pela elite, mascarou, de modo magistral, as diferenças e o preconceito, mas não reduziu as desigualdades. Em nome da miscigenação e da construção de uma ordem nacional, os grupos indígenas foram aparentemente incorporados a uma dita ordem nacional. O país da mestiçagem sustentou e sustenta a ideologia iluminista da igualdade, camuflando a realidade da desigualdade social. Essa é a realidade nacional predominante.

Para Segato (2007), a ideologia mestiça branqueada foi um fundamento ideológico de formação dos Estados pós-coloniais. A mestiçagem afirmou a igualdade como fundamento ideológico e contribuiu para a construção de uma sociedade branca e supostamente igualitária. Essa sociedade criou nichos sociais e imagens estereotipadas. Aos índios foi atribuída uma imagem de ser inculto. Os mesmos argumentos que serviram para legitimar a tomada e subjugação dos índios no passado hoje são usados para desqualificar uma pertença étnica, ou seja, sua identidade. O que estou querendo dizer é que aqueles que não correspondem à imagem convencionada de índio são deslegitimados e tidos como não índios.

Para o grande público, o índio atual é incongruente com o índio do descobrimento. As acusações acerca da ilegitimidade dos índios recaem, em inúmeros aspectos, sobre grupos populacionais no caso do Nordeste do Brasil. Pode-se citar a alegação da ausência de uma língua própria em cada grupo, pode-se alegar que não moram em ocas, dentre outros elementos percebidos como "coisa de índio". Segundo essas alegações fantasiosas, aqueles indivíduos ou grupos que não se enquadram no estereótipo são vistos como farsantes e oportunistas pobres, pois não satisfazem ao imaginário construído.

No senso comum, anedoticamente, aos índios restam as matas, os bosques e a distância da dita civilização. $O$ fato é que predomina $O$ 
imaginário estereotipado de índio e isso em muito dificulta os processos de identificação e de reafirmação étnica diante da opinião pública.

\section{O papel da cultura material no processo de afirmação étnica}

Os discursos sobre a imagem do índio se complexificam quando o assunto são os índios do Nordeste. Há menos de 50 anos não havia registros confiáveis de dados sobre a população indígena do Nordeste, ou mesmo esses índios eram tidos como inexistentes. Apesar das pesquisas e do desenvolvimento dos trabalhos e discursos, os índios misturados, como diz João Pacheco de Oliveira (1998), mesmo atualmente ainda são uma incógnita. Na mentalidade de muitos ainda paira a dúvida de como é esse índio. Como ele se veste? O que ele come? Onde ele se localiza? Contraventora de si mesma, a imagem dos índios do Nordeste é ponto de muitos questionamentos.

Os processos de identificação e de reafirmação dos povos indígenas no Brasil colocam em xeque uma série de preconceitos arraigados socialmente - preconceitos que precisam ser revistos. Os debates ganham espaço à medida que os grupos secularmente subalternizados passam a reivindicar seus direitos sem necessitar de intermediários, colocando-se como sujeitos de direitos.

No caso específico do Ceará, a primeira dificuldade do movimento indígena se encontra justamente no imaginário estático que a sociedade tem sobre o índio. Desse modo, a primeira grande batalha que alguns grupos indígenas do Nordeste enfrentam é o reconhecimento da identidade pela sociedade.

Um exemplo a ser relatado foi testemunhado por mim em Almofala² (CE), distrito que abriga o grupo Tremembé, a segunda maior etnia em número de habitantes do Estado de Ceará. Na ocasião estava na escola municipal: uma construção de aproximadamente cinco anos, toda de alvenaria e coberta com telha, salas de aula com bebedouros e sala de computação. Tem a estrutura de escola tradicional, mas é a chamada escola diferenciada.

\footnotetext{
${ }^{2}$ Distrito do município de Itarema (CE), 25 de abril de 2009.
} 
Essa denominação acontece em virtude do método e do conhecimento ensinado. As aulas têm início com o "torém" (ritual envolvendo músicas, cânticos e danças tremembés). Nessas aulas, os alunos aprendem as práticas tradicionais do povo Tremembé em meio ao ensino regular.

Voltando à minha conversa com os professores locais, fomos abordados por um senhor de aproximadamente 40 anos que perguntava pelos índios. Gostaria de saber se era verdade: "Havia ou houve, de fato, índios por aqui e se há, onde eles estão". Foi surpreendido com a afirmativa: "Há índios e o senhor está numa escola indígena". Continuou a indagar: "Mas onde estão os índios?"

"O senhor está falando com uma indígena, embora eu seja loira e tenha olho claro, eu sou tremembé de pai e mãe. Meus avós eram indígenas, apenas o pai da minha mãe era claro3".

O restante da conversa transcorreu em perguntar sobre a língua nativa, bebida, etc. Na sequência pediu para que alguém cantasse. De modo que foi perceptível a decepção do visitante e o seu desconforto com as informações e o visual da estrutura da escola. O mesmo desconforto foi vivenciado pelas professoras, que não sabiam se riam ou se explicavam o equívoco vivenciado pelo cidadão.

Essa situação é um exemplo clássico da imagem estereotipada que sociedade tem dos grupos indígenas, e do choque pelo qual ela passa ao se deparar com uma realidade diferente da idealizada. O fato é que os Tremembés não se assemelham aos índios tradicionalmente reconhecidos, como é o caso, por exemplo, dos grupos amazônicos, invocados como índios puros. Em conversa com o cacique João Venâncio momentos depois, ele foi enfático ao afirmar:

Quem vem aqui esperando a imagem [grifo meu] de um índio sem roupa tá muito enganado. Antes, na época dos nossos antepassados, nós não usava roupa porque não tinha, era tudo difícil. Minha mãe, por exemplo, lavava o cabelo com a lasca da juá, hoje tem tudo pronto, mas nós continuamos a passar para os nossos filhos e netos o conhecimento do passado. Por exemplo, nessa escola os alunos não aprende só a ler e escrever. Todo dia, antes da aula começar, eles canta o torém, o povo Tremembé é o único que tem torém.

\footnotetext{
${ }^{3}$ Referindo-se à pessoa de pele "branca".
} 
Depois ele aprende sobre importância da natureza; por que uma planta, um bicho tá doente? Nóis precisa identificar porque é da terra e do mar que a gente tira tudo pra viver (Diário de Campo, 25 abr. 2009).

Em outra ocasião ${ }^{4}$ presenciei o debate sobre o uso ou não de anticoncepcionais para mulheres indígenas. Segundo uma das debatentes, ao falar dos meios de contracepção, ela disse: "Elas deviam ter forma natural de evitar filhos. Para os índios tudo era natural".

Os dois exemplos citados demonstram que a imagem da sociedade difere da realidade dos grupos indígenas. Para a sociedade, ainda impera a imagem do índio como um selvagem seminu, com linguagem e hábitos diferentes dos brancos. Nesse contexto, os grupos indígenas do Nordeste vivem uma constante negociação entre a imagem idealizada e a sua forma de ser e estar.

Nessa arena, é perceptível a afirmação de uma identidade que requer elementos do passado, mas sem fixar-se nele. Categorias como "pajé", "aldeia" e "cacique" são invocados como aliados no processo de reconhecimento, assim como os objetos, recriando uma imagem de ser indígena na contemporaneidade.

\section{Imagens e objetos no processo de afirmação étnica}

Durante os encontros com as lideranças e as professoras do magistério indígena, observei que os grupos significam o chamado "retorno" étnico como uma volta ao passado, a partir de onde vários elementos são coadunados ao presente. As práticas passadas são ressignificadas e compreendidas à luz de uma perspectiva étnica. Algumas categorias políticas são utilizadas para restaurar a memória do grupo, seja nos rituais e nas representações políticas (cacique), seja nos procedimentos político-religiosos (pajé). Os objetos são produzidos e invocados, atuando como aliados no processo de afirmação, isto é, permitem traçar um paralelo simbólico entre o passado e o presente.

Nesse processo de reconhecimento, para alguns, a tarefa é reapropriar-se de um preconceito e positivá-lo, fazendo do fato de ser

\footnotetext{
${ }^{4}$ Fortaleza, $1^{\circ}$ de abril de 2008.
} 
índio um motivo de orgulho - apropriar-se de uma identidade histórica; para outros, é assumir no presente o passado truculento, assumindo-se como herdeiros da despossessão e prosseguir na luta pela existência e pelos direitos. Nesse caso, o passado desses índios é reinterpretado e projetado no duplo sentido do termo: por um lado, procurando satisfazer a imagem social do índio e, por outro, considerando que seu passado indígena não será jamais restituído ou remanejado sem um forte empreendimento político.

Nesse contexto de busca e negociação, os objetos são a materialidade dos saberes do passado e instrumentos de luta para o presente. Para Lima Filho (2005), o objeto e/ou coisa mesmo, que circula enquanto algo ritual praticado no corpo social, está repleto de sentidos, valores e simbolismos compartilhados socialmente. Então, os objetos, nesse prisma de interpretação, não são meros recipientes valorizados pela sua funcionalidade, mas interlocucionam, com os seus produtores e usuários, as vicissitudes da vida, comungam com a história e são, portanto, índices da comunidade.

Segundo Els Lagrou (2007), a teoria antropológica contemporânea tem renovado interesse pela vida dos objetos, assim como das imagens em seus contextos de significação. Por muito tempo, a antropologia negligenciou o estudo dos objetos como fonte de significação, voltando sua atenção a temas como parentesco, totemismo, dentre outros que se destacaram nos estudos antropológicos. Uma das questões centrais residia na tendência dos estudos em separar a estética dos objetos dos seus significados. Franz Boas foi um dos primeiros antropólogos a afirmar a universalidade do senso estético e a particularidade das manifestações tidas como artísticas. Com isso, Boas negava um evolucionismo segregador, afirmando a relatividade cultural. Para Boas, arte e cultura aparecem como categorias indissociáveis (CLIFFORD, 1988 apud ALMEIDA, 1998).

A antropologia boasiana assere o caráter significativo da arte, avançando numa perspectiva culturalista na qual a tradição tem papel fundamental na forma e no que é produzido por um grupo específico. A técnica é outro aspecto fundamental no entendimento de uma manifestação artística, ou seja, concebida como um fator ativo, possui 
um valor estético em si mesmo, pois o julgamento da forma é também um julgamento estético.

A técnica, desse modo, é uma condição para a criação. Ao contrário dos evolucionistas, que se preocupavam com a origem e a evolução das técnicas, Boas propõe uma relação inseparável entre técnica e sentido. A técnica guarda sentidos em sua criação, em que mais do que expressar o virtuosismo individual, o autor da obra pode também deixar impressos elementos inconscientes, não renegados na antropologia boasiana.

Em meados dos anos 1990, Alfred Gell propôs uma nova reflexão em relação aos estudos dos objetos. Assim, na reflexão de Gell, os objetos não são pensados como representação ou herança histórica, pois, para o autor, os objetos têm vida, são extensões das pessoas e ocupam um lugar central no meio social.

Os objetos, na sua dimensão relacional, são construtores de sentido. Quando atrelados às danças e aos cantos, performatizam as experiências do passado num processo de incorporação, abandono e mixagem, para si e para o público, criando particularidades que são o motivo de ser de cada grupo, pois, como afirmou um dos integrantes do grupo, "[...] nós desaprendemos a ser índio, agora vamos reaprender".

Indiscutivelmente, a compreensão dos objetos acrescenta novas dimensões à interpretação da história cultural, permitindo aprofundar a compreensão do universo simbólico que se exprime em sistemas de atitudes por meio dos quais os grupos sociais se definem, constroem e reconstroem identidades e apreendem mentalidades, onde os objetos são detentores de significados análogos aos fenômenos sociais e culturais estudados.

As demandas acontecem em meio a um referencial de índio onde passado e presente se coadunam numa reexperimentação onde o indivíduo rompe com a singularidade do eu, recriando um eu coletivo. $O$ uso do maracá, de saias de palha, de dançar o toré, assim como a tomada do mocororó, isso tudo ressoa nos corpos coletivos e no meio social onde a indianidade antes silenciada agora aos poucos emerge. Isso pode ser percebido não só pela incorporação de objetos e das práticas soantes, mas, acima de tudo, no reconhecimento das atividades 
cotidianas e das atitudes que passam a ser percebidas pelo crivo da pertença étnica.

\section{Os Tapuias-Kariris de São Benedito}

Segundo João Pacheco de Oliveira (1998), os índios do Nordeste não foram objeto de especial interesse na antropologia brasileira. Mudanças nas políticas públicas têm progressivamente modificado a realidade apresentada por Pacheco de Oliveira, mas, apesar do incremento de teses e publicações, ainda encontramos poucos trabalhos que tratem, em termos simbólicos, da retomada étnica desses grupos. Pelo que se sabe, essas pesquisas estão mais dedicadas a compreender essa realidade do ponto de vista político e social.

$\mathrm{Na}$ realidade, essa população, tida como inexistente e pouco estudada, vem aumentando seu contingente populacional - o que é visto por intelectuais como Pacheco de Oliveira como um paradoxo. Esse fenômeno vem ganhado espaço e fazendo com que povos que até então não se haviam reconhecido como índios passem a fazê-lo, exigindo seus direitos diante de órgãos governamentais e instituições públicas competentes.

Segundo o pajé da comunidade, um senhor de 78 anos, conhecido por todos como Ti Sé, o processo de afirmação dos Tapuias-Kariris de São Benedito teve início em 1998, quando uma moradora da região, que reside atualmente em São Paulo, afirmou seu pertencimento ao grupo indígena, mobilizando a comunidade a se organizar frente ao Estado, demandando políticas diferenciadas. Rose mobilizou todos juntamente com Chico Pai Zé, antiga liderança na comunidade.

Para Ti Sé, o processo de mobilização na comunidade foi lento, pois muitas pessoas eram contra e até hoje a comunidade se encontra completamente dividida entre aqueles que apoiam a causa e outros que acusam os índios de farsantes.

A comunidade de Carnaúba II, onde reside o grupo, está circundada por grandes fazendas. Essas fazendas são extensões de terra privada que impossibilitam o trabalho na agricultura e, consequentemente, ali fica impossibilitada a sobrevivência dos mais 
pobres. Trata-se, portanto, de um território entrecortado onde convivem os fazendeiros, os moradores que aderiram à causa indígena e alguns caseiros que, embora não sejam proprietários de terra, permanecem fiéis aos seus patrões.

O processo de reconhecimento da chamada identidade indígena é gradual e nele vários aspectos são relevantes. O primeiro deles é o reconhecimento de um passado de pobreza e trabalho - um passado de privação de possibilidades. Muitos moradores relatam um passado de longas jornadas de trabalho e de dificuldade de sobrevivência. Essas dificuldades de sobrevivência incluíam privação de praticamente tudo, de alimentos e de itens de limpeza, e, principalmente, negação de práticas culturais que caíram paulatinamente em desuso por serem consideradas como algo atrasado ou coisa de índio, como afirmou Ti Sé. Durante a pesquisa com os Tapuias-Kariris, foi relevante detectar essas histórias de maltrato, de violência e de dificuldade de emprego. O fato é que, das pessoas que aderiram ao movimento, a maioria são pessoas que trabalham ou são filhos de trabalhadores das grandes fazendas. $O$ que importa é que, em todos os casos, são pessoas conscientes do seu processo histórico de exclusão. Paralelamente ao reconhecimento da condição desse passado está a relação com o meio natural - um passado mítico glorioso de convivência com a natureza e multiplicidade de animais. Daí se constitui um discurso que busca no passado elementos para legitimar o presente, e uma espécie de resposta diante das acusações de falsa indianidade.

Ti Sé: Eu me criei dentro do mato, nóis comia bananade-raposa, nóis comia batata-doce. Fazia uma coivara grande, depois botava a batata dentro da terra e já sai assadinha, só com um pouquim de areia. Nóis comia um maracujá que chama peroba, comia o quanto queria, as terras eram libertas. Tinha um rato que chama pichuna, nóis leva sal e farinha, fazia um espeto grande.

Senhor Otávio: Nesse tempo eles chamavam a gente de índio, agora que eu assumi, ninguém quer mais que eu seja.

A memória é utilizada na reconstrução de uma pertença étnica em que elementos do passado passam a ser etnicizados e utilizados na 
elaboração de uma identidade indígena. Concomitante a esse fator, o grupo, assim como as demais etnias do Ceará, tem na afirmação identitária a peça-chave que comprova seu pertencimento étnico.

Oscilando entre tradição e modernidade, os grupos indígenas do Ceará apresentam aspectos que podem ser concebidos como tradicionais, mas não negam que são senhores e portadores de elementos culturais do seu tempo, isto é, suas práticas culturais, que não negam o diálogo com a atualidade. Um exemplo dessa oscilação entre tradição e modernidade eu observei entre os Tapebas, durante a Festa da Carnaúba. Na chegada de pesquisadores e repórteres, as crianças dançavam o toré, mas, momentos depois, longe das lentes e de observações cuidadosas, já experimentavam funk, rap, assim como cantavam músicas reproduzidas em rádios etc. Outro fato curioso foi observar que, durante o desfile de melhor traje tradicional, a performance dos meninos e das meninas segue o modelo de desfile de moda, sendo a própria proposta do desfile algo distante do que se supõe como prática indígena.

O que estou apresentando é que, no caso do processo de afirmação étnica dos índios do Ceará, o reconhecimento étnico é atravessado por uma série de variantes que perpassa diferentes prismas de realidade, da retomada do passado, do reconhecimento de um conjunto de práticas cotidianas que passaram a ser identificadas como "coisa de índio", da luta por melhores condições de sobrevivência frente a programas políticos que possibilitam a existência desses grupos, bem como da liberdade de ser, sem estar necessariamente aprisionados pelos ditames do que a sociedade impõe como prática indígena.

No processo de reconhecimento, os grupos fazem uso de uma série de elementos, como artesanatos, danças, vestimentas, culinária e rituais, dentre outras exibições. Desse modo reelaboram sua imagem em diálogo com o passado sem deixar de atualizá-la. Tais objetos ou performances procuram passar, mediante o uso de sinais diacríticos, a afirmação da identidade do grupo, formatando uma imagem de si que é ao mesmo tempo uma ação sociopolítica.

Em encontros com os Tapuias, um senhor exibiu com orgulho uma colmeia de abelhas, enquanto os demais colegas admiravam sua bravura de índio e a técnica do cacique ao pegar uma formiga. 
Imagem 1 - Práticas cotidianas.
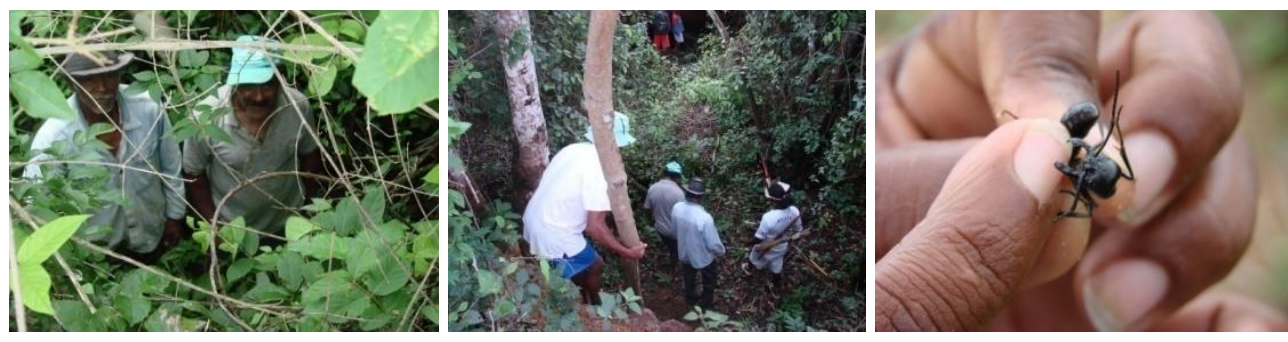

Fonte: Acervo da autora.

A noção de representação desempenha um papel fundamental na construção (social) dos significados que constituem os diferentes grupos ou culturas. No que concerne aos povos indígenas em processo de identificação, a representação dos signos étnicos - seja um mito, um gesto, uma imagem produzida tecnicamente, um objeto pessoal ou religioso, um adorno, uma pintura - possui um papel fundamental tanto para os índios quanto para o "outro". O índio ganha significado, isto é, representa ou irá representar uma ideia, um sentimento, uma emoção, um conceito intimamente ligado aos signos encontrados e associados a uma imagem. Essa imagem particular também tem representação frente ao órgão governamental que regula as questões indígenas nacionais.

Durante as festas, dentre outras celebrações, os índios apresentam-se caracterizados e de posse das coisas de índio, dizendo: "Agora vou me vestir de índio". Segundo a fala de Ti Sé, com essa afirmativa os índios apresentam uma negociação entre uma forma de ser e uma demanda social da imagem do índio.

Não se trata de uma farsa, mas de uma busca onde os elementos do passado são relembrados, apropriados e incorporados ao presente. Por isso o pajé dos Tapuias-Kariris afirmou: "Nós desaprendemos nossas práticas, mas podemos reaprendê-las". Nessa perspectiva, os objetos e as imagens são portais que permitem ao grupo a incorporação de práticas ancestrais. Eles, os objetos, são compreendidos mais no seu caráter mágico do que utilitário, que é o que acontece na atualidade com a presença do cocar e do maracá, bem como no caso do som produzido e da performance particular ao tocá-lo. 
Imagem 2: Maracá.

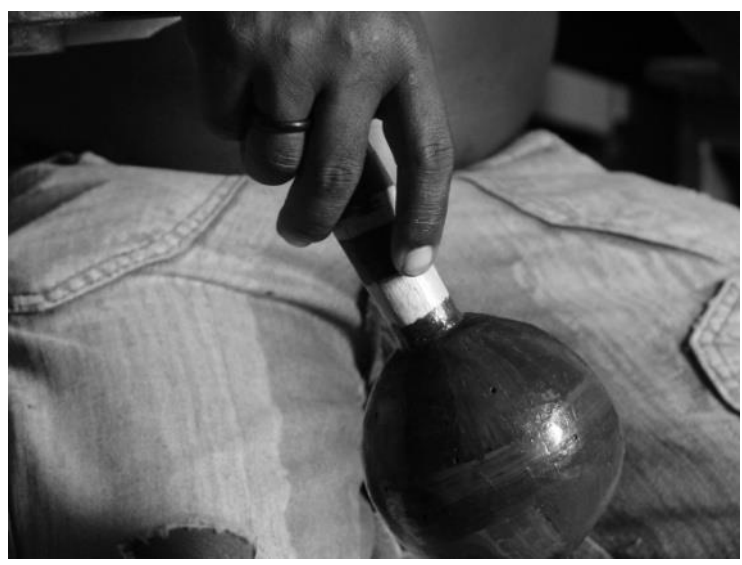

Fonte: Acervo da autora.

Nas práticas atuais desses grupos, os gestos realizados, ou objetos, são construídos e as imagens são produzidas com o sentido de reelaboração identitária e de reformulações visuais da autoimagem. Nesse processo de atualização, o passado de sofrimento e expropriação ocupa um lugar central, pois é no passado que os grupos encontram argumentos para a sua luta e dele também extraem contos e histórias que os apoiam no processo de identificação, que é também uma luta por legitimidades.

Para ilustrar essa discrepância entre passado e presente, veja-se esta fala:

Antes, aqui, a gente tinha medo de tudo, eu até hoje não sou aposentado, pois as pessoas diziam que 0 dinheiro da aposentadoria vinha do diabo, aí eu tinha medo e nunca me aposentei. Minha vida foi de muito trabalho, a gente trabalhava para ganhar isso aqui, um mocotó de réis, um quarto de um bucho, mal dava para comer, agora é que a gente tá buscando os nossos direitos, mas é porque lá em cima tem gente pela gente, senão de nada valia (Entrevista com Ti Sé, em janeiro de 2011).

O fato é que nenhum grupo é tão questionado quanto a ser ou não ser indígena quanto os índios do Nordeste. A imagem construída e alimentada pelos meios de comunicação de massa reproduzem uma perspectiva romântico-bucólica e, muitas vezes, reificadora de uma 
situação de pobreza. O potencial da cultura material e das imagens é fundamental no processo de construção e de atualização das identidades indígenas. Romper com as imagens preconceituosas que orientam as noções da pertença étnica é o primeiro passo para que os grupos indígenas possam lutar e vivenciar sua forma de ser e estar de acordo com as vicissitudes da vida.

\section{Referências bibliográficas}

AIRES, Max Maranhão Piorski et al (Org.). Direitos humanos e a questão indígena no Ceará: Relatório do Observatório Indígena, biênio 2007-2008. Fortaleza: Imprensa Universitária, 2009.

ALMEIDA, Kátia Maria Pereira de. Por uma semântica profunda: arte, cultura e história no pensamento de Franz Boas. Mana, Rio de Janeiro, v. 4, n. 2, p. 7-34, 1998. Disponível em: http://www.scielo.br/scielo.php?script=sci_arttext\&pid=S010493131998000200001\&lng=en\&nrm=iso. Acesso em: 22 jun. 2016.

GEERTZ, Clifford. A interpretação das culturas. Rio de Janeiro: LTC, 1989.

A arte como sistema cultural. In: Saber local: novos ensaios de antropologia interpretativa. Petrópolis: Vozes, 1997.

GELL, Alfred. The technology of enchantment and the enchantment of technology. In: Art and Agency. London: Clarendon Press, 1998. p. 96-123.

LAGROU, Els Maria. O que nos diz a arte kaxinawa sobre a relação entre identidade e alteridade? Mana, Rio de Janeiro, v. 8, n. 1, p. 29-61, 2002. Disponível em: http: www. scielo.br/scielo.php?script. Acesso em: 6 fev. 2009.

A fluidez da forma: arte, alteridade e agência em uma sociedade amazônica (Kaxinawma, Acre). Rio de Janeiro: Topbooks, 2007.

LIMA FILHO, Manuel Silveira; SILVEIRA, Flavio Leonel Abreu da. Por uma antropologia do objeto documental: entre a "alma das coisas" e a coisificação do objeto. Horizontes Antropológicos, Porto Alegre, v. 10, n. 23, p. 37-50, 2005.

OLIVEIRA, João Pacheco de. Uma etnologia dos "índios misturados"? Situação colonial, territorialização e fluxos culturais. Mana, Rio de Janeiro, v. 4, n. 1, p. 47-77, 1998. Disponível em: http://www. scielo.br/scielo.php?script=sci_arttext\&pid=S010493131998000100003\&lng=en\&nrm =iso. Acesso em: 5 set. 2015. 
SAMPAIO, José Augusto Laranjeiras. "De caboclo a índio": etnicidade e organização social e política entre povos indígenas contemporâneos no Nordeste do Brasil, o Caso Kapinawá. 1986. Qualificação (Mestrado em Antropologia) - UNICAMP, [1986].

SEGATO, Rita. Identidades políticas/Alteridades históricas: una crítica a las certezas del pluralismo global. In: La Nación y sus Otros: raza, etnicidad y diversidad religiosa en tiempos de Políticas de la Identidad. Buenos Aires: Prometeo Libros, 2007. p. 161-196.

ZIBAS,Dagmar M. L. Reforma do ensino médio no Ceará e suas contradições. Cadernos de Pesquisa, São Paulo, v. 35, n. 124, 2005. p. 201-226.

Recebido em: 21/05/2016* Aprovado em: 30/05/2016 * Publicado em: 30/06/2016 